Anke Walter

Erzählen und Gesang im flavischen Epos 


\section{Göttinger Forum für Altertumswissenschaft}

Beihefte

Neue Folge

Herausgegeben von Bruno Bleckmann, Thorsten Burkard, Gerrit Kloss und Jan Radicke Band 5 
Anke Walter

Erzählen und Gesang im flavischen Epos

DE GRUYTER 
Gedruckt mit Unterstützung des Förderungs- und Beihilfefonds Wissenschaft der VG WORT

ISBN 978-3-11-033620-7

e-ISBN 978-3-11-033658-0

ISSN 1866-7651

\section{Library of Congress Cataloging-in-Publication Data}

A CIP catalog record for this book has been applied for at the Library of Congress.

\section{Bibliografische Information der Deutschen Nationalbibliothek}

Die Deutsche Nationalbibliothek verzeichnet diese Publikation in der Deutschen Nationalbibliografie; detaillierte bibliografische Daten sind im Internet über http://dnb.dnb.de abrufbar.

(C) 2014 Walter de Gruyter GmbH, Berlin/Boston

Druck und Bindung: Hubert \& Co. GmbH \& Co. KG, Göttingen

@ Gedruckt auf säurefreiem Papier

Printed in Germany

www.degruyter.com 
Meiner Mutter 
